In the same year Kerr et al. from Toronto ${ }^{4}$ reported 15 patients in whom renal hypothermia had been induced by means of plastic bags containing saline slush at a temperature of just below $0^{\circ} \mathrm{C}$. This technique gave a surface cooling to 5 to $10^{\circ} \mathrm{C}$, but they stressed the difference between the central cooling of the kidney and the surface; the core temperature fell to only $22-32^{\circ} \mathrm{C}$. In 1961 Cockett from Los Angeles ${ }^{5}$ reported six further cases in which the temperature had been lowered to between 12 and $18^{\circ} \mathrm{C}$, and he claimed to have occluded the renal pedicle in these patients for periods up to 92 minutes without any noticeable permanent damage to the kidney. Wilson, ${ }^{6}$ reporting 22 cases in 1963, extended the ischaemic time to two hours at temperatures between 12 and $31.5^{\circ} \mathrm{C}$. Graves ${ }^{7}$ used $30 \%$ glycerine and water, precooled to $-3^{\circ} \mathrm{C}$, which, he said, by the time it was used in the patient had probably risen to $+2^{\circ} \mathrm{C}$. He measured the temperature of the kidney to a depth of 2 to $3 \mathrm{~mm}$ by means of a thermocouple and claimed that the cooling was, in fact, confined to the surface layers of the cortex only. He warned against too rapid cooling causing damage to the cortex of the kidney.

Up to this time most of the work on renal hypothermia had been based on the experiments carried out in sheep by Mitchell, ${ }^{8}$ but in $1967 \mathrm{Wickham}$ et al. ${ }^{9}$ made detailed studies of the biochemical function of the human kidney after renal ischaemic and showed that ten minutes warm ischaemia resulted in measurable depression of renal function which took six to seven days to recover. Thirty minutes warm ischaemia took correspondingly longer for complete recovery, and any time beyond 40 minutes of warm ischaemia resulted in some renal damage which could, perhaps, be permanent. They therefore firmly advocated that episodes of warm ischaemia should never exceed 30 minutes, and that to avoid even minimal depression of function the warm ischaemic time should not exceed ten minutes; in kidneys affected by disease these times might be too generous. They warned against lowering the temperature too far or too rapidly and pointed out that renal metabolic activity was almost fully suspended at 15 to $17^{\circ} \mathrm{C}$ so that the optimum temperature for surgical hypothermia was probably $20^{\circ} \mathrm{C}$. They found there was no permanent depression of renal function biochemically after hypothermic occlusion of the renal pedicle for periods up to 84 minutes. Wickham has recently reported ${ }^{10} 100$ cases of nephrolithotomy carried out under hypothermia and has now completed over $150,{ }^{11}$ and is preparing a simplified apparatus for inducing hypothermia which should soon be available and will reduce the process of hypothermia to a simple routine procedure.

Blandy ${ }^{12}$ and Gil-Vernet ${ }^{13}$ have argued that hypothermia is unnecessary. These critics point out that about 8 minutes of ischaemic time is lost in cooling the kidney, that the cooling is not equal throughout the depth of the kidney, and that there is no harm in perfusing the kidney by releasing the clamp for one to two minutes after 20 minutes of warm ischaemia. Furthermore Blandy does not consider that in operations such as nephrolithotomy it is necessary to remove all particles of calculi in order to relieve the patient of his symptoms, and this view further reduces the ischaemic time necessary for the operation. He was shown that in those kidneys cleared completely of stone $8.7 \%$ develop new calculi, whereas in those kidneys known to have some residual fragments only $12 \%$ produce additional stones. These figures have led some surgeons to ask whether the meticulous surgery advocated by Wickham and Mathur, ${ }^{14}$ requiring additional ischaemic time, is absolutely necessary.

In our present knowledge of renal calculi and their recurrence, however, most surgeons prefer to make every effort to remove as much calculus as possible. Most conservative renal surgery can be completed within a period of 20 minutes from closing the clamp on the renal pedicle, and as this does not result in permanent renal damage the time required to induce hypothermia is probably redundant. There are some casesstill in which 20 minutes is far too limited a time to complete the surgery necessary for adequate conservation of the kidney, and it is in these cases that hypothermia should now be considered.

1 Semb, C., Annals of the Royal College of Surgeons, 1956, 19, 137.

2 Birkeland, S., et al., The 10th International Physiological Congress, 1956, Abstracts of Communications, p. 98.

${ }^{3}$ Stewart, H. H., British fournal of Urology, 1960, 32, 392.

${ }^{4}$ Kerr, W. K., et al., fournal of Urology, 1960, 84, 236.

5 Cockett, A. T. K., Surgery, 1961, 50, 905.

${ }^{6}$ Wilson, G. S. M., Fournal of Urology, 1963, 89, 666.

7 Graves, F. T., British Fournal of Surgery, 1963, 50, 362.

${ }^{8}$ Mitchell, R. M., British fournal of Surgery, 1959, 46, 593.

Wickham, J. E. A., Hanley, G. H., and Joekes, A. M., British fournal of Urology, 1967, 39, 727 .

${ }^{10}$ Wickham, J. E. A., Coe, N., and Ward, J. P., Fournal of Urology, 1974, 112, 702 .

11 Wickham, J. E. A., personal communication.

12 Blandy, J., Annals of the Royal College of Surgeons, 1971, 48, 159.

13 Gil-Vernet, J., La Cirugia Intrasinusal de los Calculos Coraliformes, 15th Congrès de la Société Internationale d'Urologie, Tokyo, 1970, 1, 11.

14 Wickham, J. E. A., and Mathur, V. K., British fournal of Urology, 1971, 43, 648.

\section{Delay in the First Stage}

Medical writers often accuse journal editors of excessive delays in publishing their articles. Authors suspect that in the interval between submission and publication their papcrs lie around gathering dust. Faced with obscure language, faulty references, and illustrations inconsistent with the text, editors may ask why authors can't improve the presentation of their research; and, looking at the delay between the start of the project and its actual publication they may wonder why a few more weeks make such a difference.

Up to now the missing factors in this debate (usually conducted by whisper and innuendo rather than open criticism) have been the facts. But those given recently by Roland and Kirkpatrick in a study from the Mayo Clinic $^{1}$ tend to support the editorial viewpoint. The time that elapsed from the birth of the idea to the publication of the article was anything from two to four years (shortest for a case report, longest for a research article); only about a quarter of this time was spent in publishing the article and up to a half of that might be spent in assessment and getting the author to revise it. Of the 103 consecutive papers by Mayo Clinic authors questioned by Roland and Kirkpatrick, 38 were revised once at the editor's request and 8 twice; one revision did not slow down publication, but more than one revision prolonged "journal handling time" by an average of $4 \cdot 7$ months.

Some of the answers revealed a human side to medical writing. Though 87 articles listed more than one author, 28 of them were actually written entirely by a single person. Frequently, also, the first mentioned author did not write most of the article, though he might have originated the idea. None of the papers were reticent about citing work by one or more of their authors, which occupied between 10 and $20 \%$ of their references. Not unexpectedly, multi-authorship prolonged time spent in writing-from an average of 4.6 months for a paper by one author to 12.5 months for an article with several authors' names attached. Manuscripts were usually drafted in longhand and rewritten at least once by $99 \%$ of the authors and over five times by $20 \%$. Finally most clinical workers 
wrote their articles at home and most basic researchers at the office-giving, as Roland and Kirkpatrick dryly comment, the researcher one advantage over the clinician.

In other countries precise figures for the stages from hypothesis to publication would probably be different, though it seems likely that the pattern would be similar. In particular, the editorial delay for the Mayo articles might have been shortened by the prior "institutional editing" service for authors run by the clinic's excellent Department of Biomedical Communication (taking an average of 21 days, or $2 \cdot 1 \%$ of the total time). For original papers in the B.M.F. the median delay between acceptance and publication is now two months. Another three weeks are spent between receiving the manuscript and deciding on publication, mostly aided by peer review. In a stimulating address at last year's Annual Scientific Meeting, ${ }^{2}$ Douglas-Wilson attacked the refereeing system, saying that it was conservative, élitist, and even bigoted. While admitting the attraction of this argument (based as it is on our contemporary's great experience), we can only disagree; perhaps the ideal British compromise is the existing set-up-journals using both systems so that authors rejected by the one can still try the other.

Any delay in most editorial offices is still relatively small compared with that imposed by multi-authorship (eight months in the Mayo study), and postgraduate education in medical writing would almost certainly help to shorten writing time. Nevertheless, the fact remains that it takes a long time from the idea to submitting the article: "even if editor and journal processing were instantaneous, the average research idea would be about 40 months old by the time it was read." Roland and Kirkpatrick thought of their project on 24 August 1971 ; the article was published on 12 June 1975.

\footnotetext{
1 Roland, C. G., and Kirkpatrick, R. A., New England Fournal of Medicine, 1975, 292, 1273.

2 British Medical fournal, 1974, 3, 326
}

\section{Prospects for the Future}

Treatment should rarely be started before a diagnosis is established, and one of the few certainties about the reorganized N.H.S. is that there is as yet no clear agreement about its symptoms, let alone their pathogenesis. The three sessions of our Chichester conference showed the wide variations in individual assessments of the first year of the new Service: the lack of any consensus on what might or should be done next was hardly surprising. In such circumstances there are strong arguments for inaction. A major shake-up at this stage would be expensive, it would further erode the confidence of N.H.S. staff struggling to make sense of their new roles, and the last state might well be worse than first.

Much can be done, however, within the existing framework to correct qualitative defects in the way it has been working. The new system should have led to more rational policymaking, yet the familiar futile pattern is being perpetuated. The Department of Health's decisions on priorities are still issued as guidance without any recognition of their practical consequences. For example, the C.M.O. recently wrote $^{1}$ to doctors urging them to make greater efforts to secure cadaver kidneys for transplantation: presumably, therefore, the Department wants more money to be spent on the treatment of patients with renal failure, and that fact is reported in the national press. Where is the money to come from? Which acute services are to be cut back to allow an expansion in this field ? It is no answer to say that those decisions must be made locally, for if decisions on priorities should be decided by the district management team the D.H.S.S. should not pre-empt those decisions in a blaze of publicity.

The Department is also persisting in chasing unrealistic targets-for example, it has listed as a top priority the development of capital facilities for primary care, particularly health centres: yet many general practitioners want nothing to do with such projects. Inflation and Priorities, ${ }^{2}$ an assessment of the current economic situation published this week, draws attention to the paradox in that decision: "priority is being given to precisely that sector of the N.H.S. where the health authorities have least control over the use to which the money is put. ... If money is spent on family practitioners, it is anyone's guess as to who will benefit, and in what way."

Within the foreseeable future there is no prospect of any legislative action to bring the health and social services closer together; again a change in attitudes could do a lot to improve contacts. Time may lead to greater mutual trust and cooperation, but more positive efforts will be needed from both sides if real changes are to be made.

While the lack of any general agreement on any further restyling of the N.H.S. precludes national changes, there is no reason why local, experimental modifications should not be tried, and here the newly created community health councils could play a valuable part. Wales and Scotland seem to have had fewer problems in their first year than has England, and their example is a powerful argument for elimination of one of the tiers. Speakers at the conference differed on whether the region or the area could most easily be spared-or indeed whether a cross between the two might not be the ideal British compromise. There are, it seems, far too many committees, and members of district management teams argued the case for abolition of some of the advisory bodies which only duplicate each other's activities. Modifications of some kind will be needed in many parts of the country fairly soon-some district boundaries will need to be adjusted, for example, to make sense of catchment areas-and the opportunity could be taken at the same time to try the effects of putting some apparently superfluous parts of the structure into suspended animation (rather like the sleeping units of the Whitley Council system). Which committees should be phased out would be decided locally; and the practical results could then be seen of changes agreed and initiated by those most closely concerned. Surely local experimentation is better than waiting for some new set of tablets to be sent down from the mountainmistakes may be made but they are less likely to cause any lasting rancour.

"Alarm feeds on uncertainty" - as has been evident in the national economic crisis of recent weeks-and the prospects for the N.H.S. have been threatened in this way for far too long. There is still a reservoir of good will among doctors, administrators, nurses, and other N.H.S. staff, but it is being steadily eroded by their uncertainty about the Government's long-term plans for the Service (or indeed whether this Government's plans are compatible with those of any of its potential successors). Broad policy direction from the top on the distribution of resources between acute and chronic services, primary care, and preventive medicine, combined with devolution of as much decision-making as possible to the health districts, could lead to a revitalization of the N.H.S.

\footnotetext{
1 Yellowlees, H., C.M.O. 16/75. See p. 107.

2 Inflation and Priorities, ed. Rudolf Klein. London, Centre for Studies in Social Policy, 1975.
} 